\title{
Iatrogenic genitourinary fistula: an 18-year retrospective review of 805 injuries
}

\author{
Thomas J. I. P. Raassen • Carrie J. Ngongo • \\ Marietta M. Mahendeka
}

Received: 13 March 2014 / Accepted: 26 May 2014 /Published online: 26 July 2014

(C) The Author(s) 2014. This article is published with open access at Springerlink.com

\begin{abstract}
Introduction and hypothesis Genitourinary fistula poses a public health challenge in areas where women have inadequate access to quality emergency obstetric care. Fistulas typically develop during prolonged, obstructed labor, but providers can also inadvertently cause a fistula when performing obstetric or gynecological surgery.

Methods This retrospective study analyzes 805 iatrogenic fistulas from a series of 5,959 women undergoing genitourinary fistula repair in 11 countries between 1994 and 2012. Injuries fall into three categories: ureteric, vault, and vesico-[utero]/-cervico-vaginal. This analysis considers the frequency and characteristics of each type of fistula and the risk factors associated with iatrogenic fistula development.

Results In this large series, $13.2 \%$ of genitourinary fistula repairs were for injuries caused by provider error. A range of cadres conducted procedures resulting in iatrogenic fistula. Four out of five iatrogenic fistulas developed following surgery for obstetric complications: cesarean section, ruptured uterus repair, or hysterectomy for ruptured uterus. Others developed during gynecological procedures, most commonly hysterectomy. Vesico-[utero]/-cervico-vaginal fistulas were the most common (43.6\%), followed by ureteric injuries $(33.9 \%)$ and vault fistulas $(22.5 \%)$. One quarter of women with iatrogenic fistulas had previously undergone a laparotomy,
\end{abstract}

T. J. I. P. Raassen

c/o AMREF Clinical Services, P.O. Box 30125,

00100 Nairobi, Kenya

e-mail: thomasraassen@gmail.com

C. J. Ngongo $(\square)$

Fistula Care Plus, EngenderHealth, ABC Place, Rear Entrance, 2nd

Floor, Waiyaki Way, P.O. Box 57964-00200, Nairobi, Kenya

e-mail: cngongo@gmail.com

M. M. Mahendeka

Ministry of Health, Mwanza, Tanzania nearly always a cesarean section. Among these women, one quarter had undergone more than one previous cesarean section. Conclusions Women with previous cesarean sections are at an increased risk of iatrogenic injury. Work environments must be adequate to reduce surgical error. Training must emphasize the importance of optimal surgical techniques, obstetric decision-making, and alternative ways to deliver dead babies. Iatrogenic fistulas should be recognized as a distinct genitourinary fistula category.

Keywords Cesarean section · Genitourinary fistula . Hysterectomy · Iatrogenic · Ureteric injury

\section{Introduction}

A genitourinary fistula is an abnormal communication between the bladder and/or the urethra and the vagina. Most genitourinary fistulas result from prolonged, obstructed labor: the presenting part of the fetus compresses tissues against the pelvic bones, causing pressure necrosis [1]. A hole forms as the tissue dies, typically rendering the woman incontinent. Fistulas are a recurring problem in areas where women have inadequate access to quality emergency obstetric care [2].

Not all genitourinary fistulas are obstetric. Health providers may inadvertently cause injury to the urinary tract during obstetric or gynecological surgery. Other causes of fistulas include carcinoma of the cervix, radiotherapy, and sexual violence [3-5].

An iatrogenic genitourinary fistula (IF) is an abnormal communication between the bladder or ureter and the uterus/cervix/ vagina, resulting from a surgical procedure. Any surgery carries some risk of provider error. IFs are typically caused during cesarean section (CS), ruptured uterus repair, hysterectomy for ruptured uterus, and gynecological hysterectomy.

Ureteric injuries, also known as uretero-(cervico)-vaginal fistulas, are nicks, cuts, or ties in the distal ureter where it is 
nearest to the cervix. A vault fistula is a connection between the bladder and the apex of the vagina (vault), following total abdominal hysterectomy. A vesico-[utero]/-cervico-vaginal fistula (VCVF) is an accidental bladder injury (cut or suture) made during a $\mathrm{CS}$ or $\mathrm{CS} /$ subtotal hysterectomy that creates a passage between the bladder and the uterus/cervix and vagina. Waaldijk has developed a classification system for genitourinary fistulas based on anatomy and physiology [1]. Vault fistulas and VCVFs are both classified as type I; ureteric injuries as type III.

The objective of this paper is to evaluate the frequency and characteristics of IF types among fistula patients, as well as the risk factors for IF occurrence, in some countries in Africa and Asia.

\section{Materials and methods}

This retrospective record review evaluated the frequency and characteristics of IFs within a series of operations for fistulas carried out by the authors and colleagues in places where women often have inadequate access to quality emergency obstetric care. Data were collected between June 1994 and September 2012 in 65 facilities across 11 countries, mostly in eastern Africa (Table 1). The first author developed a standard form for collecting data on all women undergoing fistula repair surgery. The forms were completed by the surgeon who interviewed the patient and performed the fistula surgery. Data were then entered into an Excel database. No patient names were stored in the electronic database; each woman was instead assigned a unique patient identification number. Approval for this retrospective record review was granted by the AMREF Ethics and Scientific Review Committee. Data were analyzed using Stata software (version 2007; StatCorp, College Station, TX, USA).

The study is based on records from 5,959 women who underwent fistula repair surgery. Of these, 788 women were identified as having one or more IFs. The first and third authors interviewed all the women before surgery and performed $92 \%$ of the IF surgeries included in this data series. They assisted with or were present for the remainder. In all cases, the operating surgeon noted the classification during the fistula surgery (ureteric, vault, or VCVF).

On the basis of pre-surgery patient interviews, the operating surgeon documented the woman's age at presentation, age at fistula development, height, duration of leaking, parity, education level, living situation, and profession. The surgeon discussed whether the patient had undergone any previous laparotomies (number and type) or surgery for fistula repair (number and outcome).

The operating surgeon noted which procedure caused the IF, whether obstetric or gynecological, and the interval in days between the causative procedure and the start of leaking. The analysis divided women who developed IF following an obstetric procedure into subgroups: CS; repaired ruptured uterus; and hysterectomy for ruptured uterus (CS/hysterectomy). For obstetric IF patients, the surgeon noted the baby's sex and whether it was alive or stillborn.

For analysis, ureteric injuries were grouped according to causative surgery: CS, ruptured uterus repair, hysterectomy for ruptured uterus, or gynecological hysterectomy. All vault fistulas were caused during total abdominal hysterectomies; they were grouped according to whether the causative hysterectomy was for obstetric or gynecological indications. VCVFs were divided into those women with a live baby and those with a stillbirth. In cases of multiple births, if at least one baby was living, the mother was counted in the live-baby group. Two women had obstetric fistulas and developed vault fistulas during hysterectomies that attempted to correct urinary leaking. Given that the iatrogenic injuries occurred during their hysterectomies, they were counted in the gynecological hysterectomy group.

Iatrogenic fistulas can be considered to cover a spectrum, ranging from "definitely iatrogenic" to "likely iatrogenic." Three groups of fistulas are definitely iatrogenic. The location of ureteric injuries indicates accidental injury by a health provider. All ureteric injuries are iatrogenic, whether following CS, CS/hysterectomy, or planned gynecological hysterectomy. Vesico-vaginal vault fistulas appearing after hysterectomy for gynecological reasons, such as fibroids, are iatrogenic. Finally, the delivery of a live baby by CS is rarely associated with pressure necrosis [6]. If the baby is living, VCVF located between the lower segment of the uterus/cervix and the bladder strongly suggests an accidental bladder injury (suture or cut) during a CS.

Vault fistulas following emergency hysterectomy for a ruptured uterus or CS/hysterectomy are probably iatrogenic. A ruptured uterus can involve the bladder as well, in which case the fistula would be obstetric, but the bladder can also be damaged during dissection of the lower uterine segment and cervix, in particular when aggravated by a prior CS: through tearing and/or damaging the blood supply during blunt dissection, or including the bladder in the suture line while closing the vaginal apex.

Vesico-[utero]/-cervico-vaginal fistulas following CS for a stillborn baby are likely to be iatrogenic. In cases where the baby was lost, this analysis included VCVFs less than $3 \mathrm{~cm}$ and located clearly in the cervical canal, based on author experience. ${ }^{1}$ Women who had a ruptured uterus and stillborn baby were excluded, given the possibility of a ruptured

\footnotetext{
${ }^{1}$ In cases where the operating surgeon noted a range in estimated size ("1-2," "2-3"), we conservatively recorded the larger number. A cut-off of $2.5 \mathrm{~cm}$ would have included $97.8 \%$ of the sample (136 out of 139 ). A cut-off of $2 \mathrm{~cm}$ would have included $92.1 \%$ (128 out of 139); a cut-off of $1.5 \mathrm{~cm}$ would have included $71.2 \%$ (99 out of 139); and a cut-off of $1 \mathrm{~cm}$ would have included $52.5 \%$ (73 out of 139).
} 
bladder and therefore an obstetric rather than an iatrogenic cause. A patient history of previous CS or live birth increases the likelihood that the injury is iatrogenic.

The first author noted the cadre of health provider performing the causative procedure, on the basis of the description provided by the woman and his knowledge of local facilities and their staffing, which was complemented by input from the local staff. For this analysis, health providers were grouped as follows: clinical officers and assistant medical officers (CO/AMO); medical officers (MO); registrars; and specialists. CO/AMOs typically do not have a university qualification before completing at least 3 years of medical training and being licensed to provide general medical services. MOs have 5 years of medical training, plus an internship in medicine, pediatrics, surgery, and obstetrics/ gynecology. Registrars are residents in a medical specialty; specialists have completed residency training and are qualified in their specialty.

Of the 788 women with one or more IFs, 18 women had two types of IFs concurrently: 9 had their fistulas repaired over multiple surgeries, 8 had both fistulas repaired in one surgery, and 1 woman had only one of her injuries repaired. The frequencies of fistula characteristics according to classification considered the total of 805 IFs repaired by the author and colleagues. For example, if a woman had both a ureteric injury and a vault fistula, she was included as a member of both the ureteric and vault groups. Two women required multiple repair attempts to close a single fistula, with both surgeries performed by the author and colleagues. Only one record from each of these women was included in the analysis, so that the fistulas would not be counted twice. Data are presented according to the strength of the evidence of iatrogenic origin.

\section{Results}

The 788 women experiencing IF represent $13.2 \%$ of the 5,959 women in this series. Table 1 presents the breakdown by country. Four-fifths of the women $(632,80.2 \%)$ developed an IF following surgery for obstetric complications (Table 2). The others $(156,19.8 \%)$ developed IF following a gynecological procedure, nearly always hysterectomy. Of the 5,959 women undergoing fistula repair, $9.5 \%$ had a fistula in one of the "definitely iatrogenic" categories outlined in the Materials and methods section. The cumulative percentage of "definitely" or "probably iatrogenic" was $11.0 \%$, while the cumulative percentage of "definitely," "likely," or "probably iatrogenic" was $13.2 \%$ (Fig. 1).

Women in the obstetric group were generally younger, shorter, and had suffered longer with their fistula compared with those in the gynecological group (Table 3).
Table 1 Women with iatrogenic fistula: country of repair

\begin{tabular}{lll}
\hline Country & \multicolumn{2}{l}{ Iatrogenic fistulas } \\
\cline { 2 - 3 } & $n$ & $\%$ \\
\hline Tanzania & 286 & 36.3 \\
Uganda & 238 & 30.2 \\
Kenya & 162 & 20.6 \\
Rwanda & 47 & 6.0 \\
Malawi & 22 & 2.8 \\
South Sudan & 9 & 1.1 \\
Zambia & 6 & 0.8 \\
Ethiopia & 6 & 0.8 \\
Somalia & 5 & 0.6 \\
Bangladesh & 4 & 0.5 \\
Afghanistan & 3 & 0.4 \\
Total & 788 & \\
\hline
\end{tabular}

In addition to iatrogenic injuries, 28 women (3.6 \%) had obstetric fistula and 2 women had perineal tears at the time of presentation. Eight women had undergone successful fistula repair in the past, for a previous or concurrent fistula. A total of 45 women $(5.7 \%)$ had undergone at least one past unsuccessful attempt at surgery, whether for an iatrogenic or concurrent obstetric fistula.

Of the 805 IFs, 273 (33.9\%) were ureteric injuries, 181 $(22.5 \%)$ were vault fistulas, and $351(43.6 \%)$ were VCVFs (Table 2). Over half of the procedures resulting in IF were CS (462, $57.4 \%$; Table 2). Hysterectomy was the next most frequent cause, accounting for 317 iatrogenic injuries (39.4\%): 159 hysterectomies were for ruptured uterus $(19.8 \%)$ and $158(19.6 \%)$ were for gynecological indications. Twenty-five women (3.1\%) were injured during repair of a ruptured uterus; 1 was injured during an induced abortion.

Medical officers (MOs) performed over half of the causative procedures $(474,58.9 \%$; Table 4$)$. Clinical officers/ assistant medical officers (CO/AMOs) performed 231 causative procedures overall $(28.7 \%)$ and $73.8 \%$ of the 313 procedures in Malawi and Tanzania. Specialists performed $78(9.7 \%)$, while registrars performed $22(2.7 \%)$.

A quarter of the women with IF had undergone previous laparotomy (201, $25.5 \%$; Table 5). A quarter (24.9\%) of these women had undergone more than one laparotomy. Nearly all laparotomies $(197,98.0 \%)$ were CS; others were bilateral tubal ligation, myomectomy, and salpingectomy.

Ureteric injuries

The 273 ureteric injuries constituted $33.9 \%$ of the 805 IFs considered (Table 2). More than three-quarters (211 out of $273,77.3 \%$ ) of the ureteric injuries occurred following obstetric procedures. Half of the ureteric injuries occurred during 
Table 2 Procedures in which iatrogenic fistula occurred

\begin{tabular}{|c|c|c|c|c|c|c|c|}
\hline \multirow[t]{3}{*}{ Procedure causing iatrogenic fistula } & \multicolumn{7}{|c|}{ Waaldijk classification } \\
\hline & \multicolumn{2}{|c|}{ Type I (vesico-cervico-vaginal fistula) } & \multicolumn{2}{|c|}{ Type II (vault fistula) } & \multicolumn{2}{|c|}{ Type III (ureteric injury) } & \multirow[t]{2}{*}{ Total $(100 \%)$} \\
\hline & $n$ & $\%$ & $n$ & $\%$ & $n$ & $\%$ & \\
\hline \multicolumn{8}{|l|}{ Obstetric procedures } \\
\hline Cesarean section & 324 & 70.1 & 0 & 0 & 138 & 29.8 & 462 \\
\hline Repair of ruptured uterus & 9 & 36.0 & 0 & 0 & 16 & 64.0 & 25 \\
\hline Hysterectomy for ruptured uterus & 16 & 10.0 & 86 & 54.1 & 57 & 35.8 & 159 \\
\hline \multicolumn{8}{|l|}{ Gynecological procedures } \\
\hline Gynecological hysterectomy & 1 & 0.6 & 95 & 60.1 & 62 & 39.2 & 158 \\
\hline Other & 1 & 100.0 & 0 & 0 & 0 & 0 & 1 \\
\hline Total & 351 & & 181 & & 273 & & 805 \\
\hline
\end{tabular}

CS (138, 50.6\%). Sixteen ureteric injuries (5.9\%) followed a repair of a ruptured uterus, while 57 (20.9\%) presented following a hysterectomy for ruptured uterus. Sixty-two ureteric injuries (22.7\%) followed gynecological hysterectomy.

Medical officers performed over half $(145,53.1 \%)$ of the procedures causing ureteric injury. CO/AMOs performed 93 (34.1\%), specialists $26(9.5 \%)$, and registrars $9(3.3 \%)$. The mean interval between the causative procedure and the start of leaking was 10.4 days; the median was 7 days (IQR: 3-14). The left ureter was more likely to be injured than the right: 169 cases $(61.9 \%)$ vs 104 cases $(38.1 \%)$. Five women had injuries to both ureters. Thirty-one women with ureteric injury had undergone one or more previous CS (Table 5).

\section{Vault fistulas}

The 181 vault fistulas represented $22.5 \%$ of the 805 IFs considered (Table 2). The vault fistulas were all caused during a total abdominal hysterectomy: 95 (52.5\%) for gynecological reasons and $86(47.5 \%)$ for a ruptured uterus.

Medical officers performed $95(52.5 \%)$ of the procedures that caused vault fistula; specialists, 48

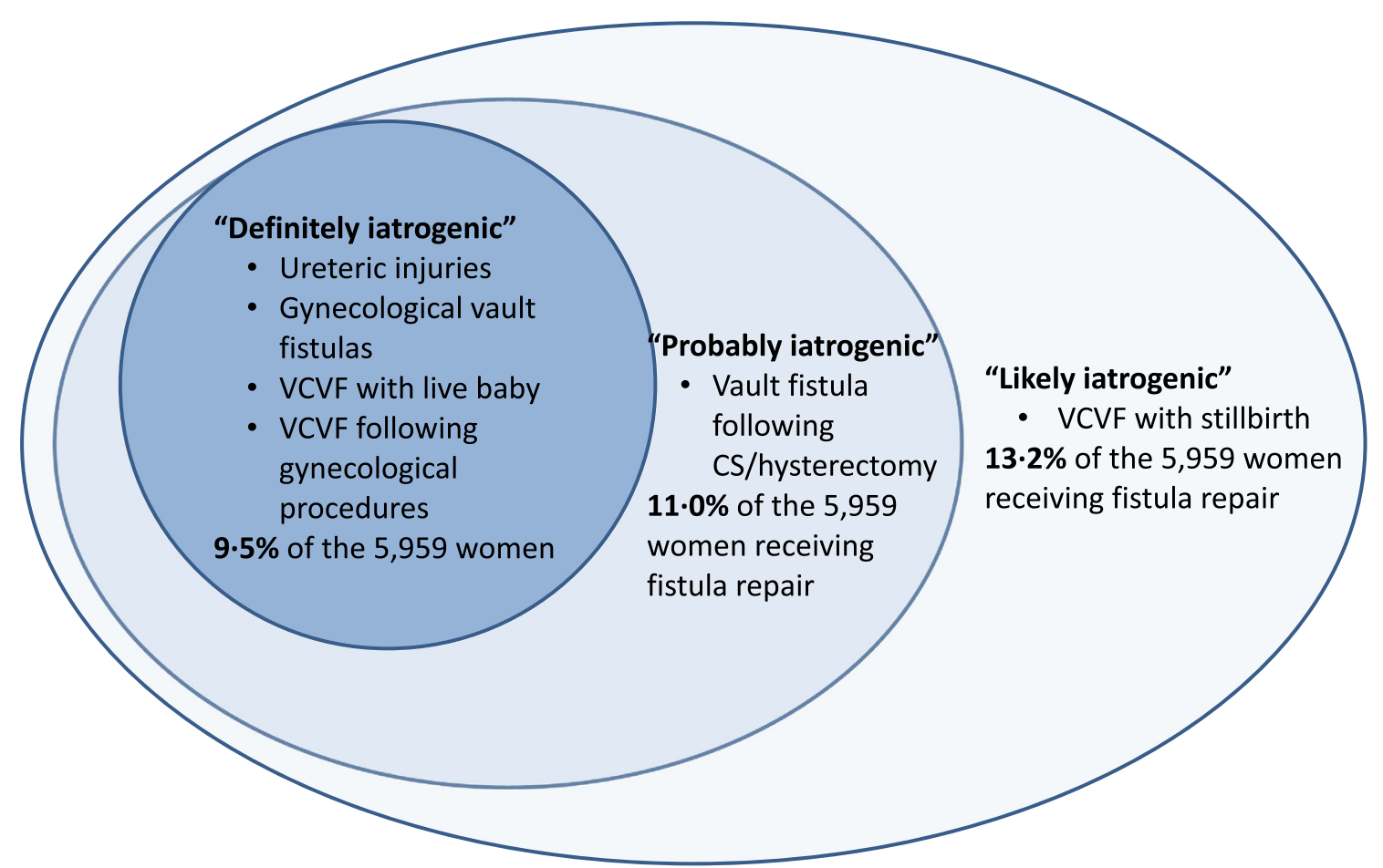

Fig. 1 Conceptual categorization of iatrogenic fistulas 
Table 3 Demographic profile of iatrogenic fistula patients, by causative procedure type

\begin{tabular}{lllc}
\hline & $\begin{array}{l}\text { Obstetric cause } \\
(n=632 \text { women }) \\
\text { Mean, SD (range) }\end{array}$ & $\begin{array}{l}\text { Gynecological cause } \\
(n=156 \text { women }) \\
\text { Mean, SD (range) }\end{array}$ & $p$ value \\
\hline Age at fistula occurrence & 28.6 years, $6.9(13-48)$ & 41.9 years, $8.5(24-76)$ & 0.000 \\
Age at time of fistula repair & 31.5 years, $8.5(14-61)$ & 44.0 years, $8.5(25-76)$ & 0.000 \\
Height & $153.3 \mathrm{~cm}, 6.4(128-171)$ & $158.5 \mathrm{~cm}, 8.0(115-179)$ & 0.000 \\
Parity & $4.5,2.7(1-12)$ & $4.2,3.2(0-15)$ & 7.35 \\
Duration of leaking & $13.6 \%$ primiparous & $9.2 \%$ nulliparous & -0.68 \\
\hline
\end{tabular}

(26.5\%); CO/AMOs, 30 (16.6\%); registrars, 8 (4.4\%). The mean interval between the causative procedure and the start of leaking was 7.0 days; the median was 3 days (IQR: 0-8).

\section{Vesico-[utero]/cervico-vaginal fistulas}

The 351 VCVFs represent $43.6 \%$ of the 805 IFs (Table 2). Nearly all VCVFs were associated with obstetric procedures (349, $99.4 \%$ ), with 210 associated with a live birth and 139 associated with a stillbirth. The remaining two VCVFs followed gynecological procedures (1 subtotal hysterectomy and 1 induced abortion).

Over $40 \%$ of women with VCVF (141) had undergone a previous laparotomy, all CS. Women who gave birth to live babies were more likely to have had a previous CS than women who experienced stillbirth (Table 5). MOs performed $66.7 \%$ of the causative operations (234), CO/AMOs performed $30.8 \%$ (108), registrars $1.4 \%$ (5), and specialists $1.1 \%$ (4). All but one of the VCVFs associated with stillbirth were caused during $\mathrm{CS}$. The mean interval between the causative procedure and the start of leaking was 4.8 days; the median interval was 2 days (IQR: $0-7$ ).

\section{Discussion}

Obstetric fistula is a recognized consequence of health system failure and the inability of the world's poorest and most marginalized women to access emergency obstetric care [2]. This study considers a sample of women - over $13 \%$ of those presenting for fistula repair surgery-who suffered not directly because of prolonged, obstructed labor, but because of accidents caused by health providers. The prevalence of IF points to gaps in the quality of obstetric and gynecological surgery. The characteristics of iatrogenic injuries prompt us to consider opportunities to improve the quality of service provision.

A range of obstetric and gynecological procedures led to the development of IF, including CS (57.4\%), CS/ hysterectomy (19.8\%), gynecological hysterectomy $(19.6 \%)$, ruptured uterus repair $(3.1 \%)$, and induced abortion $(0.1 \%)$. Other surgeries, such as destructive vaginal

Table 4 Cadre of staff performing causative procedure, by procedure

\begin{tabular}{|c|c|c|c|c|c|c|c|c|c|}
\hline \multirow[t]{3}{*}{ Procedure causing iatrogenic fistula } & \multicolumn{8}{|c|}{ Cadre of staff performing causative procedure } & \multirow[t]{3}{*}{ Total $(100 \%)$} \\
\hline & \multicolumn{2}{|c|}{ Clinical officer/assistant medical officer } & \multicolumn{2}{|c|}{ Medical officer } & \multicolumn{2}{|c|}{ Registrar } & \multicolumn{2}{|c|}{ Specialist } & \\
\hline & $n$ & $\%$ & $n$ & $\%$ & $n$ & $\%$ & $n$ & $\%$ & \\
\hline \multicolumn{10}{|l|}{ Obstetric procedures } \\
\hline Cesarean section & 148 & 32.0 & 297 & 64.3 & 10 & 2.2 & 7 & 1.5 & 462 \\
\hline Repaired ruptured uterus & 10 & 40.0 & 14 & 56.0 & 1 & 4.0 & 0 & 0 & 25 \\
\hline Hysterectomy for ruptured uterus & 41 & 25.8 & 102 & 64.2 & 6 & 3.8 & 10 & 6.3 & 159 \\
\hline \multicolumn{10}{|l|}{ Gynecological procedures } \\
\hline Gynecological hysterectomy & 31 & 19.6 & 61 & 38.6 & 5 & 3.2 & 61 & 38.6 & 158 \\
\hline Other & 1 & 100 & 0 & 0 & 0 & 0 & 0 & 0 & 1 \\
\hline Total & 231 & & 474 & & 22 & & 78 & & 805 \\
\hline
\end{tabular}


Table 5 Previous laparotomy among women with iatrogenic fistula

\begin{tabular}{|c|c|c|c|c|c|c|c|c|c|c|c|}
\hline & \multirow[t]{3}{*}{ Fistulas } & \multirow[t]{3}{*}{ Women } & \multirow{2}{*}{\multicolumn{2}{|c|}{$\begin{array}{l}\text { Women with previous } \\
\text { laparotomy }\end{array}$}} & \multicolumn{6}{|c|}{$\begin{array}{l}\text { Among women with previous laparotomy, } \\
\text { number of laparotomies undergone }\end{array}$} & \multirow[t]{3}{*}{ Type of laparotomy } \\
\hline & & & & & \multicolumn{2}{|l|}{1} & \multicolumn{2}{|l|}{2} & \multicolumn{2}{|l|}{3} & \\
\hline & & & $n$ & $\%$ & $n$ & $\%$ & $n$ & $\%$ & $n$ & $\%$ & \\
\hline Total & 805 & $788^{\mathrm{b}}$ & 201 & 25.5 & 151 & 75.1 & 42 & 20.9 & 8 & 4.0 & $\begin{array}{l}98 \% \text { CS } \\
2 \% \text { other }\end{array}$ \\
\hline Ureteric injury & 273 & 268 & 31 & 11.6 & 20 & 64.5 & 9 & 29.0 & 2 & 6.5 & $100 \% \mathrm{CS}$ \\
\hline Vault fistula & 181 & 181 & 31 & 17.1 & 24 & 77.4 & 4 & 12.9 & 3 & 9.7 & $\begin{array}{l}87 \% \text { CS } \\
13 \% \text { other }^{\mathrm{c}}\end{array}$ \\
\hline $\begin{array}{l}\text { VCVF: overall } \\
\text { Live baby }\end{array}$ & $\begin{array}{l}351^{\mathrm{a}} \\
210\end{array}$ & $\begin{array}{l}351^{\mathrm{a}} \\
210\end{array}$ & $\begin{array}{l}141 \\
102\end{array}$ & $\begin{array}{l}40.2 \\
48.6\end{array}$ & $\begin{array}{l}108 \\
76\end{array}$ & $\begin{array}{l}76.6 \\
74.5\end{array}$ & $\begin{array}{l}30 \\
23\end{array}$ & $\begin{array}{l}21.3 \\
22.6\end{array}$ & $\begin{array}{l}3 \\
3\end{array}$ & $\begin{array}{l}2.1 \\
2.9\end{array}$ & $100 \% \mathrm{CS}$ \\
\hline Stillbirth & 139 & 139 & 39 & 28.1 & 32 & 82.0 & 7 & 18.0 & 0 & 0 & \\
\hline
\end{tabular}

${ }^{a}$ The two women with vesico-[utero]/-cervico-vaginal fistulas (VCVF) following gynecological procedures are not included in either subgroup

${ }^{\mathrm{b}}$ Women with multiple iatrogenic fistulas are counted once in each applicable group

${ }^{\mathrm{c}}$ Other laparotomies included bilateral tubal ligation, myomectomy, and salpingectomy

operations or symphysiotomy, also carry risks of accidental harm from the provider [7], but none was reported to be a causative procedure in this series.

Data on whether the causative CSs were elective or emergency were not collected, but data on the duration of labor suggest that 15 women had an elective CS (labor $\leq 1 \mathrm{~h}$ ). The mean duration of labor reported by the remaining women who underwent CS or CS/hysterectomy was $39.7 \mathrm{~h}$. Women experiencing obstetric complications frequently present to the hospital late, and providers may have had inadequate time to prepare their patients [8]. The availability of skilled professionals able to perform surgery is likely to be particularly low outside of normal working hours $[8,9]$.

The median age of women who developed IF during a gynecological procedure was 42 years, which is consistent with the patient population requiring gynecological procedures and is in line with published data $[8,10,11]$. The median age of women who developed IF during an obstetric procedure was 28 years, older than the age reported for most obstetric fistula patients $[3,5,12,14]$.

Several factors are suspected to place a woman at risk of IF. These include prior uterine operation, endometriosis, cervical myoma, and prior pelvic radiation $[10,11,14]$. Scar tissue and adhesions from prior laparotomies can create challenges for providers performing obstetric and gynecological surgery. It is therefore reasonable to hypothesize that obstetric or gynecological surgery might carry a greater risk of iatrogenic injury for women who have undergone a laparotomy in the past [10]. The frequency of previous laparotomy in the general population is unknown, but in this sample of women with IF, a full quarter had undergone one or more previous laparotomies. One quarter of the women who had had a previous laparotomy had undergone more than one. In this series, $98.0 \%$ of previous laparotomies were cesarean sections.

The different types of IF were not equally associated with previous laparotomy. Under $12 \%$ of ureteric injuries and $17.1 \%$ of vault fistulas occurred in women who had undergone previous laparotomy, but $40.2 \%$ of women with VCVF had undergone at least one previous laparotomy. Among VCVF patients, previous CS was more common in women who delivered a live baby than in those with a stillbirth ( $48.6 \%$ vs $28.1 \%$ ). Providers are more prompt in providing CS to women with a previous CS, and more often as an elective procedure.

While appropriate cesarean sections improve maternal and perinatal outcomes, they do not confer similar advantages when performed in low-risk groups [15]. The World Health Organization has pointed out the intrinsic risk associated with CS [16]; yet, obstetric practice is shifting from vaginal to cesarean birth in many parts of the world, including in some of the countries included in this study [15-18]. It would seem that one risk associated with CS, particularly repeated CS, is that providers might be more likely to accidentally cause iatrogenic injury during a subsequent surgery.

Early detection of IF can help patients avoid prolonged morbidity and its consequences. Early management of IFs should be feasible, so long as providers recognize the problem $[8,14,19]$. Providers can identify many IFs when removing the Foley catheter shortly after surgery. Excluding ureteric injuries, a substantial number of small IFs could be healed by re-introducing the catheter and leaving it for a period of 4 6 weeks, with a regimen of plenty of oral fluids and sitz baths [20].

The median time before patients began leaking among those with a VCVF or vault fistula was 2 and 3 days respectively, and 7 days after the causative surgery in those with 
ureteric injury. In this analysis, IFs following gynecological hysterectomy were treated earlier than those following obstetric surgeries. Differences in patient populations may explain this finding: gynecological patients are mainly self-referred, establishing a relationship with a provider who may recognize the problem and ensure appropriate care. If the leaking starts after discharge, the patient will go back to the operating provider and will be referred appropriately. Obstetric patients typically arrive as emergencies, and the operating provider may not see the patient after her CS. Moreover, leaking after an emergency CS could be due to pressure necrosis; providers may not immediately recognize the iatrogenic cause.

It appears that the ureters are not at equal risk of being accidentally damaged during CS $[8,21]$. The left ureter is more likely to be affected during CS for several reasons. First, it is half a centimeter nearer to the cervix than the right ureter [22]. Second, the large sigmoid colon in African women causes dextro-rotation of the gravid uterus, bringing the left ureter forward [23]. Finally, many right-handed operators stand on the right side of the patient when performing CS, making it more likely to inadvertently injure the left ureter.

All cadres of health providers in this series performed procedures that resulted in IF, from assistant medical officers to specialists. National data on the cadres of staff performing different types of procedures are typically unavailable, but the profile described here is not surprising based on the human resources in the countries involved. Medical officers are typically the most likely cadre to carry out emergency surgeries such as CS or CS/hysterectomies; thus, their role in $59 \%$ of IFs likely reflects their high involvement in at-risk procedures.

In both Malawi and Tanzania, nonphysician clinicians perform the majority of obstetric surgery. In Malawi, $88 \%$ of emergency obstetric operations in district hospitals are performed by clinical officers [24]. In one study in Tanzania, more than $85 \%$ of obstetric and gynecological surgeries were performed by assistant medical officers [25]. In light of this, the $73.8 \%$ of IFs caused by CO/AMOs in Malawi and Tanzania seems reasonable. In all countries, specialists would be more likely to conduct elective procedures than emergency ones. This explains why specialists performed only $9.6 \%$ of the causative procedures, but $38.6 \%$ of the gynecological hysterectomies that resulted in IF.

This analysis has several limitations. First, the women themselves provided much of the information recorded in the patient records. While women mostly know their obstetric histories, recall can be a challenge. In some cases, providers may not have fully educated patients about procedures performed and the reasons for performing them. The fistula surgeon's assessment complemented each woman's account, helping to determine the most likely obstetric history. The first author's determination of the cadre causing IF was dependent on his and his colleagues' knowledge of local facilities and their staffing, which could be subject to recall bias and may be difficult for others to reproduce. Finally, these data do not indicate the overall prevalence of IF, but instead point to the proportion of fistula of iatrogenic origin among women in need of fistula repair surgery. This series of IF repairs was drawn from a sample of nearly 6,000 fistula repairs that took place in 65 facilities across 11 countries, ranging from subdistrict hospitals to tertiary referral facilities. Reliable population-level information about fistula prevalence is unavailable, as is information about the total number of obstetric and gynecological surgical procedures performed. This means that some of the denominators that would put the findings into context are unavailable.

Prevention of IF is an urgent matter that needs to be addressed in developing countries. Providers performing obstetric and gynecological surgery must have the appropriate competencies. Training, combined with mentoring and ongoing supervision, is essential. In addition, women with obstructed labor must be able to quickly access a health facility with the staffing and infrastructure to provide highquality emergency obstetric care. As such, it is critical to strengthen referral systems (emergency communication and transport) and address financial barriers that result in delays in care-seeking behavior. Training and equitable deployment of skilled birth attendants at all levels of the health system will ensure that providers can recognize signs of abnormal labor progression and make appropriate decisions about referral. Such efforts should be complemented by community-level interventions that promote household preparation for birth, increase male partner involvement in maternal health, and empower women to take action to ensure their own health and well-being.

Whenever women arrive at facilities in need of care, it is critical that providers are able to make informed and timely decisions. Facilities and providers must consider the quality of emergency obstetric care, including the decision-making process leading to a CS. The partograph is an essential tool for monitoring progress in labor and for diagnosing obstructed labor [26]. Providers must manage women in labor according to best medical practice; some women wait hours or days in a hospital before receiving any intervention [27, 28]. Facilities must likewise treat providers fairly, compensating them for their service and providing adequate resources, training, and supervision.

Providers must have the knowledge and experience to be able to provide high-quality services. As shown elsewhere $[6,7]$, the high number of cesarean deliveries for dead infants emphasizes the importance of re-evaluating alternative vaginal delivery methods. Many providers may benefit from training on alternatives to cesarean section, including vacuum extraction, symphysiotomy, and craniotomy for dead babies. Provider training should likewise highlight optimal operative techniques [9]. In dissection of the bladder and the lower uterine segment, blunt dissection can 
damage blood supply to the bladder, especially if the patient has had a previous CS. Sharp dissection is always preferable $[14,22]$. The training, mentoring, and supervision of providers will improve care and therefore the health outcomes of women.

Acknowledgements We thank the African Medical and Research Foundation (AMREF), EngenderHealth, the Fistula Foundation, the Freedom from Fistula Foundation, Gesellschaft für Technische Zusammenarbeit (GTZ; now GIZ), Johnson \& Johnson, the Royal Netherlands Embassy of Tanzania, SOS East Africa, United Nations Population Fund (UNFPA), and especially Women and Health Alliance International (WAHA) for supporting the first and third authors in traveling to the many hospitals. The United States Agency for International Development (USAID), through EngenderHealth's Fistula Care project, funded the data analysis and writing. Millicent Oundo graciously took on the difficult task of entering data from patient forms and establishing a database. Jane Carter and Brian Hancock reviewed the article and offered expert advice. We thank the specialists and staff in the hospitals, who operated on the women and managed them during their hospital stays. Last but not least, we thank all the women who allowed us to help them, and showed their gratitude with unforgettable smiles.

\section{Conflicts of interest None.}

Open Access This article is distributed under the terms of the Creative Commons Attribution License which permits any use, distribution, and reproduction in any medium, provided the original author(s) and the source are credited.

\section{References}

1. Waaldijk K (1995) Surgical classification of obstetric fistulas. Int J Gynecol Obstet 49:161-163

2. Osotimehin B (2013) Obstetric fistula: ending the health and human rights tragedy. Lancet 381:1702-1703. doi:10.1016/S0140-6736(13) 61001-6

3. Raassen TJIP, Verdaasdonk EGG, Vierhout ME (2008) Prospective results after first-time surgery for obstetric fistulas in East African women. Int Urogynecol J 19:73-79. doi:10.1007/s00192-007-0389-6

4. Qureshi ZP, Raassen TJIP (1998) Vesico-vaginal fistulae occurring after total abdominal hysterectomy. J Obstet Gynaecol East Central Afr 14:115-117

5. Zheng AX, Anderson FWJ (2009) Obstetric fistula in low-income countries. Int J Gynecol Obstet 104:85-89. doi:10.1016/j.ijgo.2008. 09.011

6. Hancock B, Collie M (2004) Vesico-vaginal fistula surgery in Uganda. East Cent Afr J Surg 9:32-37

7. Onsrud M, Sjoveian S, Mukwege D (2011) Cesarean delivery-related fistulae in the Democratic Republic of Congo. Int J Gynaecol Obstet 114:10-14. doi:10.1016/j.ijgo.2011.01.018

8. Obarisiagbon EO, Olagbuji BN, Onuora VC, Oguike TC, Ande ABA (2011) Iatrogenic urological injuries complicating obstetric and gynaecological procedures. Singapore Med J 52:738-741

9. Rajasekar D, Hall M (1997) Urinary tract injuries during obstetric intervention. Br J Obstet Gynaecol 104:731-734

10. Mathevet P, Valencia P, Cousin C, Mellier G, Dargent D (2001) Operative injuries during vaginal hysterectomy. Eur J Obstet Gynecol Reprod Biol 97:71-75
11. Mteta KA, Mbwambo J, Mvungi M (2006) Iatrogenic ureteric and bladder injuries in obstetric and gynaecologic surgeries. East Afr Med J 83:79-83

12. Hawkins L, Spitzer RF, Christoffersen-Deb A, Leah J, Mabeya H (2013) Characterisitics and surgical success of patients presenting for repair of obstetric fistula in western Kenya. Int J Gynaecol Obstet 120:178-182

13. Landry E, Frajzyngier V, Ruminjo J, Asiimwe F, Barry TH, Bello A, Dantani D, Ganda SO, Idris S, Inoussa M, Kanoma B, Lynch M, Mussell F, Podder DC, Wali A, Mielke E, Barone MA (2013) Profiles and experiences of women undergoing genital fistula repair: findings from five countries. Glob Public Health 8(8):926-942. doi: 10.1080/ 17441692.2013 .824018

14. Tancer ML (1992) Observation on prevention and management of vesicovaginal fistula after total hysterectomy. Surg Gynecol Obstet 175:501-506

15. Litorp H, Kidanto HL, Nystrom L, Darj E, Essén B (2013) Increasing caesarean section rates among low-risk groups: a panel study classifying deliveries according to Robson at a university hospital in Tanzania. BMC Pregnancy Childbirth 13:107. doi:10.1186/14712393-13-107

16. World Health Organization (2010) Caesarean section without medical indication increases risk of short-term adverse outcomes for mothers. Policy brief. Geneva. http://whqlibdoc.who.int/hq/2010/ WHO_RHR_HRP_10.20_eng.pdf. Accessed 16 July 2013

17. Belizan JM, Althabe F, Cafferata ML (2007) Health consequences of the increasing caesarean section rates. Epidemiology 18:485-486

18. Leone T, Padmadas SS, Matthews Z (2008) Community factors affecting rising caesarean section rates in developing countries: an analysis of six countries. Soc Sci Med 67:1236-1246. doi:10.1016/j. socscimed.2008.06.032

19. Blandy JP, Badenoch DF, Fowler CG, Jenkins BJ, Thomas NWM (1991) Early repair of iatrogenic injury to the ureter or bladder after gynecological surgery. J Urol 146:761-765

20. Waaldijk K (2004) The immediate management of fresh obstetric fistulas. Am J Obstet Gynecol 191:795-799

21. Goodwin WE, Scardino PT (1980) Vesicovaginal and ureterovaginal fistulas: a summary of 25 years of experience. J Urol 123:370-374

22. Shaw RW, Monga A, Luesley D (2010) Gynaecology, 4th edn. Livingstone, Churchill

23. Dutton FL, Geelhoed GW (2005) Basic obstetrics and obstetric surgery in a mission setting. In: Geelhoed GW (ed) Surgery and healing in the developing world. Landes Bioscience, Georgetown, p 137. http://www.dartmouth-hitchcock.org/dhmc-internet-upload/ file_collection/geelhoed_surgery.pdf. Accessed 16 Aug 2013

24. Chilopora G, Pereira C, Kamwendo F, Chimbiri A, Malunga E, Bergstrom S (2007) Postoperative outcome of caesarean sections and other major emergency obstetric surgery by clinical officers and medical officers in Malawi. Hum Resour Health 5:17

25. McCord C, Mbaruku G, Pereira C, Nzabuhakwa C, Bergstrom S (2009) The quality of emergency obstetrical surgery by assistant medical officers in Tanzanian district hospitals. Health Aff (Millwood) 28:w876-w885

26. Mathai M (2009) The partograph for the prevention of obstructed labor. Clin Obstet Gynecol 52:256-269

27. Bowser D, Hill K (2010) Exploring evidence for disrespect and abuse in facility-based childbirth: report of a landscape analysis. http:// www.tractionproject.org/sites/default/files/upload/RFA/Respectful\% 20Care \%20at\%20Birth\%209-20-101\%20Final.pdf Accessed 19 Aug 2013

28. Thaddeus S, Maine D (1994) Too far to walk: maternal mortality in context. Soc Sci Med 38:1091-1110 